\title{
EFFICACY OF SUPPLEMENTATION OF PROBIOTICS ALONG WITH ANTIMICROBIAL AGENTS IN VULVOVAGINAL INFECTIONS IN A TERTIARY CARE HOSPITAL
}

\section{DEEPA PATIL ${ }^{1}$, GEETHA ${ }^{2}$, RAGHUPRASADA MALLADAR SHIVAMURTHY ${ }^{*}$, UMAKANT N PATIL ${ }^{4}$}

${ }^{1}$ Department of Pharmacology, Basaveshwara Medical College and Hospital, SJMIT Campus, Chitradurga, Karnataka, India. ${ }^{2}$ Department of Pharmacology, East Point College of Medical Sciences and Research Centre, Cheemasandra, Bidrahalli, Bengaluru, Karnataka, India.

${ }^{3}$ Department of Pharmacology, S S Institute of Medical Sciences and Research Center, Davangere, Karnataka, India. ${ }^{4}$ Department of Pharmacology, Basaveshwara Medical College and Hospital, SJMIT Campus, Chitradurga, Karnataka, India. Email: raghuprasada@gmail.com

Received: 30 September 2021, Revised and Accepted: 03 November 2021

\section{ABSTRACT}

Objectives: The objectives of the study were to ascertain the efficacy of probiotics along with antimicrobials in the treatment of vulvovaginitis and to evaluate the rate of recurrence.

Methods: The study was done on 60 patients who were randomly selected and divided into two groups of 30 each. Prior permission from the Institutional Ethics Committee and higher authorities was obtained before conducting the study. One group received standard treatment including antibacterial, antiviral, and antifungal as per the gynecologist discretion and in other group along with standard treatment, probiotic capsules containing combination of Saccharomyces boulardii, Lactobacillus sporogenes (50 million), Streptococcus faecalis (30 million), Clostridium butyricum ( 2 million), and Bacillus mesentericus (1 million) given orally twice daily and followed up for a period of 3 months. The drugs were started on the $5^{\text {th }}$ day after menstruation taking starting of the bleeding as day 1.

Results: The parameters compared were symptoms and signs (significantly reduced - p-value), clue cells (significantly reduced in number), and recurrence rates (significantly reduced), in $80 \%$ of patients smears which were not consistent with BV. Maximum number of patients showed negative $\mathrm{KOH}$ mount (71.5\%), saline wet mount was negative in $80 \%$ of patients in antimicrobial agents + probiotics group.

Conclusion: From the present interventional study, probiotics along with antimicrobial agents showed better improvement than antimicrobial agents alone. Hence, supplementation of probiotics along with antimicrobial agents provides better efficacy than antimicrobial agents alone in treating vulvovaginal infections

Keywords: Vulvovaginal infections, Trichomoniasis, Candidiasis, Bacterial vaginosis, Probiotics, Antimicrobial agents.

(C) 2021 The Authors. Published by Innovare Academic Sciences Pvt Ltd. This is an open access article under the CC BY license (http://creativecommons.org/ licenses/by/4.0/) DOI: http://dx.doi.org/10.22159/ajpcr.2021v14i12.43269. Journal homepage: https://innovareacademics.in/journals/index.php/ajpcr

\section{INTRODUCTION}

Female lower genital tract, consisting of vagina and ectocervix, is biological niche where numerous aerobic and anaerobic microorganisms coexist in a dynamic balance. In fertile, premenopausal healthy women, the vaginal ecosystem is dominated by lactobacilli (L) species but a diverse array of other bacteria can be present in much lower numbers. L. crispatus, L. inners, L. jensenii, and L. gasseri are the predominant vaginal Lactobacillus species. Lactobacilli are implicated in regulating the normal vaginal microbiota by preventing overgrowth of pathogenic bacteria and opportunistic organisms [1].

Vulvovaginitis is defined as an inflammation of the vulva and vagina. It is the most common gynecological condition constituting about $25 \%$ of outpatients. The common forms of infectious vulvovaginitis are bacterial vaginosis $(40-50 \%)$, candidiasis $(20-25 \%)$, and trichomoniasis $(15-20 \%)$ all with high rates of recurrence $[2,3]$. Bacterial vaginosis (BV) is one of the most common causes of genital discomfort in women, affecting about $19-24 \%$ in reproductive age group [4]. The prevalence of bacterial vaginosis varies in different parts of the world and it is higher in developing countries [5]. It is believed to occur as a result of an imbalance in the normal vaginal microbiota and is characterized by reduction in native lactobacilli and subsequently replaced by anaerobic bacteria $[6,7]$. Up to $10-15 \%$ of patients fail to respond to initial antimicrobial therapy and recurrence rates are significant (up to $80 \%$ ) and requiring repeated administration of antimicrobial agents. Such repeated exposure increases the risk of emergence of resistant strains, alteration of microbiota, and possible persistence of bacterial vaginosis associated pathogens [4]. Vulvovaginal candidiasis (VVC) is estimated to be the second most common form of vaginitis after bacterial vaginosis [8]. Although antifungal agents are quite effective in VVC, resistance to the drugs is increasing. In addition, drugs may reduce the normal protective vaginal flora to increase the risk of recurrent infections and can also cause many adverse effects $[9,10]$.

As antimicrobial treatment of urogenital infections is not always effective and problems remain due to bacterial and yeast resistance, recurrent infections, as well as side effects of drugs, it is no surprise that alternative remedies are of interest to patients and health caregivers [11]. Under normal physiological setting, the patient's own lactobacilli would come back after antimicrobial therapy and colonize the vagina, thereby conferring some protection from infection. The additional use of probiotics is designed to enhance this process [12]. This led to the idea of replacing the depleted lactobacilli using probiotic strains as a therapeutic approach.

\section{METHODS}

This clinical study was carried out in the department of pharmacology and obstetrics and gynecology, of a tertiary care teaching hospital of Central Karnataka over the period of one and half year.

The study included 60 patients, divided into two groups of 30 patients each. After obtaining ethical committee clearance from the Institutional Ethical Review Board, one group received standard regular treatment (the standard regular treatment may include antibacterial, antiviral, 
and antifungal as per the gynecologist discretion) and in other group along with standard treatment, probiotic capsules containing combination of Saccharomyces boulardii, Lactobacillus sporogenes (50 million), Streptococcus faecalis (30 million), Clostridium butyricum ( 2 million), and Bacillus mesentericus (1 million) given orally twice daily for 1 month as add on treatment and follow-up was done for a period of 3 months. The drugs were started on the $5^{\text {th }}$ day after menstruation taking starting of the bleeding as day 1 . Informed consent was taken from all the patients. Statistical analysis was done using Student's t-test.

$\mathrm{n}=60$, consisting of two groups.

Group 1 = Antimicrobial agents alone and Group $2=$ Antimicrobial agents + Probiotics capsules

\section{Inclusion criteria}

The following criteria were included in the study:

1. Female patients aged between 18 and 45 years (mean age 35 years)

2. Patients willing to give written informed consent

3. Clinical diagnosis of vulvovaginitis confirmed by any one of the tests such as Amsel's criteria, Nugent score, $\mathrm{KOH}$ wet mount test, and saline wet mount test

4. Presence of at least one vulvovaginal symptom (vulvovaginal itching, white discharge per vagina, burning, and irritation) or at least one vulvovaginal sign (vulvovaginal erythema, edema, and excoriation)

5. Patients who were newly diagnosed and/or recurrent vulvovaginitis not treated in the previous 1 month.

\section{Exclusion criteria}

The following criteria were excluded from the study:

1. Pregnant or nursing women

2. Patient menstruating at the time of diagnosis

3. Usage of antibacterial drugs either systemically or intravaginally within the past 2 weeks

4. Patients already on medications for vulvovaginitis

5. Patients taking immunosuppressive or immunostimulating medications and systemic corticosteroids within 3 months before study

6. Patients involved in any other study in previous 1 month

7. Patients with comorbid conditions such as diabetes mellitus and sexually transmitted diseases such as gonorrhea, syphilis, chlamydia, and AIDS

8. Patients with a history of allergy to metronidazole, clotrimazole, and clindamycin

9. After history, detailed systemic and local examination including per speculum and per vaginal examination was done to know the type of discharge and other signs of vaginal infection by gynecologist.

\section{Specimen collection}

Vaginal discharge is collected from the posterior fornix with the help of sterile swab and the following tests were done:

Gram staining, $\mathrm{KOH}$ preparation, and saline wet mount.

\section{Efficacy parameters [13]}

1. Vaginal discharge by participant report: The grading was given in the following manner

Grade $0=$ Participants usual amount of discharge regardless of color or quantity (Normal discharge)

Grade 1 = Mild-moderate increase in amount above participant baseline - no sanitary protection is required (Mild discharge)

Grade 2 = Profuse increase in discharge requiring pad use or other hygienic intervention (Moderate discharge).

2. Dysuria - The grading was given in the following manner.

Grade $0=$ None

Grade $1=$ Superficial only

Grade $2=$ Deep \pm superficial

Grade 3 = Inability to void due to pain.
3. Dyspareunia - The grading was given in the following manner.

Grade $0=$ None

Grade 1 = Pain causing no or minimum interference with sexual dysfunction

Grade 2 = Pain causing greater than minimal interference with sexual dysfunction

4. Vulval/Vaginal Itching - The scoring was given in the following manner.

Grade $0=$ None

Grade 1 = Itching causing no, mild, or moderate interference with usual social and functional activities

Grade 2 = Itching causing inability to perform usual social and functional activities, may require intervention such as antihistamine or bathing to provide relief.

5. Vaginal discharge as reported by clinician [13]:

Grade $0=$ Slight amount of discharge, any color

Grade $1=$ Mild-moderate increase in amount

Grade 2 = Significant increase in amount with pooling in vagina examination .

1. Vaginal erythema:

Grade $0=$ None

Grade $1=$ Erythema covering $<50 \%$ of vaginal surface

Grade 3 = Erythema covering $>50 \%$ of vaginal surface.

2. Vaginal tenderness [13]:

Grade $0=$ None

Grade 1 = Mild tenderness

Grade 2 = Moderate tenderness

Grade 3 = Severe tenderness

\section{Types of outcome measures}

Vaginal swabs were collected - 0 (before treatment), 7, 28, 60, and 90 days post-treatment.

Outcome measures:

\section{Primary outcomes measures}

1. Nugent score $-1=$ Smear not consistent with bacterial vaginosis and $2=$ Smear consistent with bacterial vaginosis

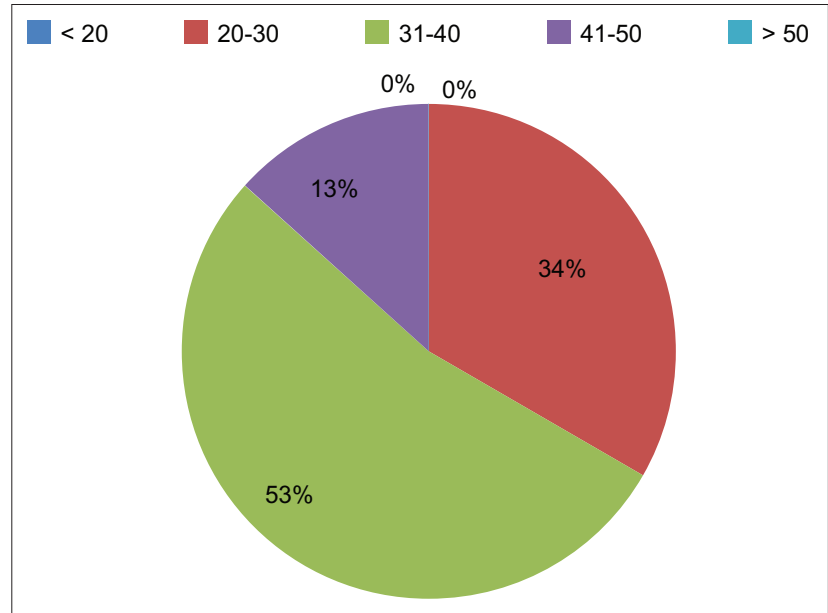

Fig. 1: Age-wise distribution of patients

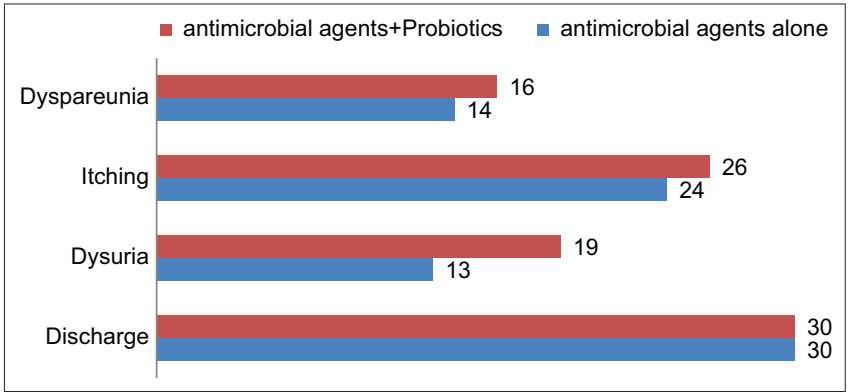

Fig. 2: Symptoms presentation 
2. Clue cells $-1=$ Absent and $2=$ present

3. KOH mount $-1=$ Negative for Candida and $2=$ Positive for Candida

4. Saline wet mount $-1=$ Negative for Trichomonas and $2=$ Positive for Trichomonas

\section{Secondary outcome measures}

- Symptoms as reported by the patient.

1 = Improvement of symptoms

2 = No improvements

- Clinical cure as reported by the physician or investigator.

$1=$ Improvement in signs

2 = No improvement in signs

- Persistence or recurrence of bacterial vaginosis at follows up (from 30 days post-treatment)

$1=$ Smear consistent with bacterial vaginosis

$2=$ Smear not consistent with bacterial vaginosis

\section{RESULTS}

The results are based on data collected having demographic profile, pharmacological treatment prescribed, and clinical outcome.

There was no significant difference in the mean age between the two groups. Fig. 1 shows that $53 \%$ of patients were between 31 and 40 years age group and $34 \%$ were between 21 and 30 years age group, indicating that vulvovaginal infections are more common in reproductive age groups (18-45 years).

The independent sample ' $t$ ' test for nugent's score at the end of 90 days showed significant ' $\mathrm{P}$ ' value $(\mathrm{P}<0.00)$ (Table 1$)$. The saline wet mount at the end of followup on applying pearson chi-square test showed significant results $(\mathrm{P}<0.005)$ (Table 2$)$. $\mathrm{KOH}$ mount at the end of followup was only $2 \%$ (28.5\%) with probiotics and antimicrobial group (Table 3 ).

\section{DISCUSSION}

Efficacy of oral supplementation of probiotics along with antimicrobial agents is determined by assessing the patients for improvement of

Table 1: KOH mount at the end of follow-up period

\begin{tabular}{lll}
\hline KOH mount & $\begin{array}{l}\text { Antimicrobial agents } \\
\text { alone (\%) }\end{array}$ & $\begin{array}{l}\text { Antimicrobial agents + } \\
\text { Probiotics (\%) }\end{array}$ \\
\hline $\begin{array}{l}\text { Post-treatment } \\
\text { (90 days) }\end{array}$ & $5(71.4)$ & $2(28.5)$ \\
\hline
\end{tabular}

Table 2: Saline wet mount at the end of follow-up

\begin{tabular}{llll}
\hline Groups & \multicolumn{2}{l}{$\begin{array}{l}\text { Saline wet mount } \\
\text { (\%) }\end{array}$} & Total \\
\cline { 2 - 3 } & Positive & Negative & \\
\hline Antimicrobial agents alone & $7(70)$ & $3(30)$ & 10 \\
Antimicrobial agents + Probiotics & $2(20)$ & $8(80)$ & 10 \\
Total & 9 & 11 & 20 \\
\hline
\end{tabular}

Pearson Chi-square value $-5.051 . P=0.025(p \leq 0.05$, significant $P$ value $)$

Table 3: Presence of clue cells at the end of 90 days

\begin{tabular}{lll}
\hline Clue cells & $\begin{array}{l}\text { Antimicrobial } \\
\text { agents alone (\%) }\end{array}$ & $\begin{array}{l}\text { Antimicrobial agents + } \\
\text { Probiotics (\%) }\end{array}$ \\
\hline $\begin{array}{l}\text { 90 days (end of } \\
\text { follow-up period) }\end{array}$ & $6(46.1)$ & $2(15.3)$ \\
\hline
\end{tabular}

symptoms, signs, Nugent scoring, and recurrence rate over the period of 3 months. Patients in both the groups received antimicrobial agents according to gynecologist discretion except the second group where along with the antimicrobial agents patients also received probiotics capsules twice daily for 30 days.

The study is suggestive of useful effects of probiotics supplementation in the treatment of VVC (Table 1). Even though treatment of yeast vaginitis, mainly with topical antimycotic drugs, is practically effective, recurrences are very frequent. Resistance to these drugs is growing because many women self-diagnose, self-treat, and option of over-thecounter antifungal medications [14]. Normal vaginal microenvironment is largely populated by Lactobacillus species, which tend to keep a check on the growth of other bacterial species. This domination of lactobacilli and their potential capability to resist VVC gave rise to the concept of oral or vaginal instillation of probiotic Lactobacillus strains to restore the vaginal microbiotic equilibrium [10]. The results of study by Martinez et al. indicate that probiotics can be successfully used in treatment of Candida infections may be because of inhibition of the growth of Candida albicans in the vagina and strengthening of the immune system in the vagina, small bowel, and colon and reduction of fungi in the rectum and vagina [15].

In the present study, it is seen that in antimicrobial agents + probiotic group significant number of patients were negative for saline wet mount $(80 \%)$ after treatment period. This is indicative of beneficial effects of probiotics in Trichomonas infections. p-value was significant (Table 2).

In the present study, the number of patients positive for clue cells was significantly less $(15.3 \%)$ in antimicrobial agents + probiotics group (Table 3). We also compared mean value of Nugent scoring using independent sample "t-test." There was a significant reduction in the mean value in antimicrobial agents + probiotics group (Table 4) and the mean difference is also very high and is highly significant (Table 5). We got significant p-value after applying unpaired "t-test" to Nugent scoring in between the groups. There was a significant increase in the number of patients with smear not consistent with BV (Table 6) in antimicrobial agents + probiotics group at the end of follow-up period which is similar to a study conducted by Anukam, where efficacy of combining probiotics or placebo with oral metronidazole was assessed in women aged 18-44 years. Study conducted by Bradshaw et al., using oral metronidazole $400 \mathrm{mg}$ BD for 7 days followed by vaginal pessary containing L. acidophilus, reported similar results [1] At the end of follow up period symptoms and signs were significantly reduced in probiotics plus antibiotics group (Tables 7 and 8) similar results were found in a study done by Martinez et al.[9].

Prevention of recurrent BV in healthy women is an important issue In the present study reccurence rate was significantly reduced in probiotic plus antimicrobial agent group (Table 9) similar findings were noted in Mastromarino et al. study. [1] In majority of trials, the route of Lactobacillus was intravaginal. However, some investigators reported repopulation of vagina with oral probiotics. This was based on the observation that pathogens can pass from the gut into the urogenital system and recovery of lactobacilli from vagina after their oral administration [1].

As antimicrobial treatment of urogenital infections is not efficient for all time and troubles remain due to bacterial and yeast resistance, recurrent infections, as well as side effects of drugs, it is no surprise that alternative remedies are of interest to the patients and their health caregivers. One of the reasons for recurrent infection may be abolition of the commensal microorganisms in the vagina by the antimicrobials,

Table 4: Independent sample "t-test" - Nugent score at 90 days

\begin{tabular}{|c|c|c|c|c|c|c|c|}
\hline Groups & $\mathbf{N}$ & Mean & Std. deviation & Difference & $\mathbf{t}$ & Df & p-value \\
\hline Antimicrobial agents alone & 13 & 5.8462 & 2.51151 & -4.15385 & 4.174 & 24 & 0.000 \\
\hline Antimicrobial agents + Probiotics & 13 & 1.6923 & 2.56205 & & & & \\
\hline
\end{tabular}


Table 5: Interpretation of Nugent scoring using independent sample "t-test"

\begin{tabular}{|c|c|c|c|c|c|c|c|}
\hline Groups & Mean & $\mathbf{N}$ & Std. deviation & Mean difference & $\mathbf{T}$ & Df & p-valve \\
\hline \multicolumn{8}{|c|}{ Antimicrobial agents alone } \\
\hline \multicolumn{8}{|c|}{ Pair 1} \\
\hline Nugent0 & 9.15 & 13 & 1.345 & 3.308 & 6.813 & 12 & $<0.001$ \\
\hline Nugent90 & 5.85 & 13 & 2.512 & & & & \\
\hline \multicolumn{8}{|c|}{ Antimicrobial agents + Probiotics } \\
\hline \multicolumn{8}{|c|}{ Pair 1} \\
\hline Nugent0 & 9.0 & 13 & 1.291 & 7.308 & 10.417 & 12 & $<0.001$ \\
\hline
\end{tabular}

Table 6: Interpretation of Nugent scoring at the end of 90 days

\begin{tabular}{lll}
\hline $\begin{array}{l}\text { Nugent's score at the } \\
\text { end of 90 days }\end{array}$ & $\begin{array}{l}\text { Smear } \\
\text { consistent with } \\
\text { BV (\%) }\end{array}$ & $\begin{array}{l}\text { Smear not } \\
\text { consistent with } \\
\text { BV (\%) }\end{array}$ \\
\hline $\begin{array}{l}\text { Antimicrobial agents } \\
\text { alone }\end{array}$ & 53.80 & 46.20 \\
$\begin{array}{l}\text { Probiotics + } \\
\text { Antimicrobial agents }\end{array}$ & 15.40 & 84.60 \\
\hline
\end{tabular}

Table 7: Symptoms reported by the patient

\begin{tabular}{lll}
\hline Symptoms & $\begin{array}{l}\text { Present } \\
\text { (\%) }\end{array}$ & $\begin{array}{l}\text { Absent } \\
\text { (\%) }\end{array}$ \\
\hline Antimicrobial agents alone & 66.60 & 33.40 \\
Probiotics + Antimicrobial agents & 16.60 & 83.40 \\
\hline
\end{tabular}

Table 8: Signs as reported by the physician at the end of 90 days

\begin{tabular}{lll}
\hline Signs & Present & Absent \\
\hline Antimicrobial agents alone & 60 & 40 \\
Probiotics + Antimicrobial agents & 20 & 80 \\
\hline
\end{tabular}

Table 9: Recurrence rate at the end of follow-up period

\begin{tabular}{lll}
\hline Groups & $\begin{array}{l}\text { Recurrence } \\
\text { (\%) }\end{array}$ & $\begin{array}{l}\text { Non-recurrence } \\
\text { (\%) }\end{array}$ \\
\hline $\begin{array}{l}\text { Antimicrobial agents alone } \\
\text { Probiotics + Antimicrobial }\end{array}$ & 63.30 & 36.70 \\
agents & 20 & 80 \\
\hline
\end{tabular}

thereby rising vulnerability to recolonization by pathogens. This is one of the main reasons to reestablish the commensal bacteria as a way to lower the risk of reinfection [1].

\section{CONCLUSION}

At the end of 3 months follow-up, probiotics along with antimicrobial agents showed significant improvement in symptoms and signs, Nugent score was towards normal, $\mathrm{KOH}$ mount and saline wet mount tests were negative, and decreased recurrence rate. Hence, oral supplementation of probiotics along with antimicrobial agents showed better efficacy. The use of probiotics to prevent infection has a good rationale and anexcellent safety record, but so far only a few strains have been clinically proven to be effective, in particular to prevent BV. It is criticallyimportant that strains be characterized and tested clinically using the delivery system of choice (oral, vaginal, dried powder, or in suspension).

The value of probiotics supplementation in vaginal infections other than candidiasis, bacterial vaginosis, and trichomoniasis needs to be explored. Many more studies are needed to optimize the defensive properties of the vaginal microbiota but the potential remains that health of many women can be improved by probiotics intervention [1].

\section{ACKNOWLEDGMENTS}

I want to thank Indian Council of Medical Research for funding this project.

\section{AUTHORS' CONTRIBUTIONS}

Author 1: Case collection, preparation of manuscript, and editing. Author 2: Preparation of manuscript and proofreading and case collection. Author 3: Statistical analysis, manuscript preparation, and proofreading. Author 4: Manuscript preparation and proofreading

\section{CONFLICTS OF INTEREST}

No.

\section{REFERENCES}

1. Mastromarino P, Vitali B, Mosca L. Bacterial vaginosis: A review on clinical trials with probiotics. New Microbiol 2013;36:229-38.

2. Cannoni BG, Borquez RS. Vavlovaginitis and sexually transmitted infections in adolescence. Rev Med Clin Condes 2011;22:49-57.

3. Santos AR, Pereiro M Jr., Toribio J. Recurrent vulvovaginitis: Diagnostic assessment and therapeutic management. Actas Dermosifiliogr 2008;99:190-8.

4. SenokAC, Verstraelen H, Temmerman M,Botta GA. Probiotics for the treatment of bacterial vaginosis. Cochrane Database Syst Rev 2009;4:CD006289.

5. Larsson PG, Bergstrom M, Forsum U, Jacobsson B, Strand A, Wolner-Hanseen P. Bacterial vaginosis. Transmission, role in genital tract infection and pregnancy outcome: An enigma. APMIS 2005; 113:233-45.

6. Eriksson K, Carlsson B, Forsum U, Larsson PG. A double blind treatment study of bacterial vaginosis with normal vaginal Lactobacilli after an open treatment with vaginal clindamycin ovules. Acta Derm Venereol 2005;85:42-6.

7. Ya W, Reifer C, Miller LE. Efficacy of vaginal probiotic capsules for recurrent bacterial vaginosis: A double blind randomized, placebo controlled study. Am J Obstet Gynaecol 2010;203:120-5.

8. Vicariotto F, Del Piano M, Mogna L, Mogna G. Effectiveness of the association of two probiotic strains formulated in a slow release vaginal product, in women affected by vuvlovaginal candidiasis: A pilot study. J Clin Gastroenterol 2012;46:S73-80.

9. Martinez RC, Franceschini SA, Patta MC, Quintana SM, Candido RC, Ferreira JC, et al., Improved treatment of vulvovaginal candidiasis with fluconazole plus probiotic Lactobacillus rhamnosus GR-1 and Lactobacillus reuteri RC-14. Lett Appl Microbiol 2009;48:269-74.

10. Xie HY, Feng D, Wei DM, Chen H, Mei L, Wang F, et al. Probiotics for vuvlovaginal candidiasis in non pregnant women. Cochrane 2013;4:1-63.

11. Cribby S, Taylor M, Reid G. Vaginal microbiota and the use of probiotics. Inetrdiscip Perspect Infect Dis 2008;2008:256490.

12. Anukam K, Osazuwa E, Ahonkhai I, Ngwu M, Osmene G, Bruce AW, et al. Augmentation of antimicrobial metronidazole therapy of bacterial vaginosis with Lactobacillus rhamnosus GR-1 and Lactobacillus reuteri RC-14: Randomized, double blind, placebo controlled trial. Microbes Infect 2006;8:1450-4.

13. Division of AIDS table for Grading the Severity of Adult and Pediatric Adverse Events. Published Date: December 2004. Available from: http:// www.rsc.tech_res.com/Documents/Safetyandpharmacovigilance/ Addendum_1_Female_Genital Grading_Table_V1_Nov 2007.Pdf

14. Waigankar SS, Patel $\bar{M}$. Role of probiotics in urogenital health. J Med Health 2012;2:5-10.

15. Nouraei S, Akbari SA, Jorjani M, Majd HA, Afrakhteh M, Ghafoorian A, et al. Comparison between fluconazole with oral protexin combination and fluconazole in the treatment of vulvovaginal candidiasis. Obstet Gynecol 2012;2012:375806. 